\title{
СОЦИАЛЬНАЯ СПРАВЕДЛИВОСТЬ НАЛОГООБЛОЖЕНИЯ ЖИЛОЙ НЕДВИЖИМОСТИ И ЕЕ ОЦЕНКА
}

\begin{abstract}
Аннотация. Объектом представленного в статье исследования является жилая недвижимость. Предметом исследования - социальная справедливость налогообложения жилой недвижимости, выступающая как малоформализуемая, обобщенная, субъективно обусловленная экономическая категория. Автор формулирует основные дискуссионные вопросы: справедливо ли в целом налогообложение жилой недвижимости, которая представляется социально значимым объектом, сучетом объективно возникающих затрат и выгод, какой известный метод налогообложения укладывается в рамки справедливости и можно ли формально оценить справедливость размера налога, порождаемого любой моделью налогообложения? Методология исследования базируется на анализе и систематизации теоретических работ многочисленных авторов относительно справедливости налогообложения жилья и на выборочном обследовании объектов жилой недвижимости, с целью разработки инструмента формальной оценки социальной справедливости размера налога. Научная новизна исследования состоит в адаптации ценового дифференциала, известного в теории оценки недвижимости инструмента, коценке социальной справедливости размера налога, генерируемого любой (действующей или теоретической) моделью налогообложения. В статье инструмент получил название «дифференциал вертикальной равномерности налогообложения». С его помощью произведена оценка социальной справедливости действующей модели налогообложения в Кыргызской Республике.

Ключевые слова: дифференциал вертикальной равномерности, горизонтальная равномерность, вертикальная равномерность, метод налогообложения, модель налогообложения, прогрессивность налогообложения, справедливость налогообложения, налог на жилье, жилая недвижимость, оценка справедливости.
\end{abstract}

Abstract. The object of the given research is the residential real estate. The subject of the research is the social justice of the residential real estate taxation as a low formalized, generalized and subjectively determined economic category. The author of the article formulates the main debating points such as whether the taxation of residential real estate is fair in general as a socially important object taking into account objective costs and benefits, which known method of taxation answers the principle of justice and whether it is possible to give a formal evaluation of fairness of the tax amount generated by any model of taxation. The methodology of the research is based on the analysis and systematization of theoretical researches of numerous authors regarding justice of the residential taxation as well as selective observation of residential real estate objects for the purpose of developing tools for the formal evaluation of the social justice of the tax amount. The scientific novelty of the research is caused by the fact that the author adjust the price differential known in the theory of residential real estate evaluation to evaluation the social justice of the tax amount generated by any (existing or theoretical) model of taxation. The author calls the inventory 'the differential of the taxation vertical uniformity'. Using this inventory, the author evaluates the social justice level of the current taxation model in the Kyrgyz Republic.

Keywords: differential of the vertical uniformity, horizontal uniformity, vertical uniformity, taxation method, taxation model, justice of taxation, progressive taxation, housing tax, residential real estate, justice evaluation.

оциальная справедливость является самым важным и более всего обсуждаемым, как в профессиональной среде, так и среди игроков, находящихся внутри налоговой системы, принципом налогообложения. С ней ассоциируется малоформализуемая обобщенная характеристика налоговой системы или даже отдельного налога, которая не позволяет дать четкое определение этой категории.
Присущая справедливости малоформализуемость и высокая степень субъективизма в ее понимании разными слоями общества, и даже отдельными ее представителями, оставляют вопрос справедливости открытым и дискуссионным в любой налоговой системе в любой период времени.

Русские экономисты, мыслители и практики, такие как: Алексеев А. А., Витте С. 


\section{Налогообложение физических лиц}

Ю., Исаев А.А., Озеров И. Х., Соколов А. А., Столыпин П. А., Тургенев Н. И., Янжул И. И. и др. писали о справедливости налогообложения, как о понятии относительном, зависящем от места, времени, представлений, классовости общества и от принадлежности налогоплательщика к определенной социальной группе. Следует отметить, что поскольку каждый член общества - потенциальный налогоплательщик, то понятие справедливости чаще всего рассматривается с точки зрения физического лица, хотя не следует исключать и другую справедливость, основанную на том, что налоговые доходы - основной источник государственных расходов. Очень четко эту мысль сформулировал Глуховский Я. Ю. «Налогоплательщики часто и в очень разных ситуациях ссылаются на налоговую справедливость. Однако преимущественно они связывают ее со снижением налоговой нагрузки либо с полным освобождением от налогов. В данном случае имеет место субъективная справедливость, обусловленная защитной реакцией налогоплательщика на утрату части принадлежащих ему материальных средств в результате налогообложения. Такая справедливость порождает у налогоплательщика стремление уменьшить собственные налоги, в сочетании с предъявлением требований кпубличной власти по выполнению ею различного рода обязательств. Однако имеется и другое, объективное понимание справедливости, которое имеет практическое значение, поскольку это понимание органов власти, которые облагают налогами. Оно сводится к тому, что покрытие публичных расходов связано с необходимостью подбора источников доходов и справедливого распределения налоговой нагрузки среди экономических субъектов» [1].

Таким образом, рассматривая социальную справедливость налогообложения жилой недвижимости как отдельную категорию, следует дать ответы на несколько вопросов, а именно:

- справедливо ли в целом налогообложение жилой недвижимости?

- если да, то какой метод налогообложения будет укладываться в рамки справедливости?

- можно ли оценить справедливость размера налога, порождаемого используемой моделью налогообложения?
Исследуя первый из поставленных вопросов, следует отметить, что многие авторы выражали свое мнение по этому поводу, но если резюмировать многочисленные идеи, то складывается картина, сфокусированная на трех направлениях:

1. Налог на жилую недвижимость - это справедливый налог и надежный источник для пополнения местных бюджетов. Справедливость основана на том, что владельцы жилого недвижимого имущества ежедневно и ежечасно пользуются общественными благами - дорогами, инженерными коммуникациями, общественной инфраструктурой, и т.д., финансирование на поддержание и развитие которых идет из местных бюджетов, а те, в свою очередь, пополняются, в том числе, и за счет налога на жилье [2]. Следует отметить, что владельцы жилья, как правило, недовольны уровнем и качеством предоставления общественных благ, но не связывают это со своими обязательствами по уплате налогов.

2. Органы государственной власти и местного самоуправления должны поощрять жилищное строительство и создавать условия для реализации права граждан на жилище, одновременно, они заинтересованы в любых источниках налоговых поступлений для пополнения местных бюджетов. Очевидно, что налог на жилую недвижимость приведет к увеличению текущих расходов семей, использующих собственное жилье для целей проживания, а для тех семей, которые по различным причинам вынуждены снимать жилье, налог на жилую недвижимость будет являться косвенным налогом, который полностью войдет в стоимость аренды, в то время как собственники доходного жилья (жилья, сдаваемого в аренду), не будут иметь обременений от налога. Это может привести к нежелательным социальным последствиям, поскольку вопрос налогообложения жилья затрагивает большую часть населения. [3]. В таком случае, налог на жилье может затруднить для граждан возможность реализовывать конституционное право на жилище.

3. Не кажется справедливым, что жилье, купленное на доходы, с которых был уплачен налог, вновь подвергается налогообложению, при том, что регулярный ремонт жилья и поддержание его в удовлетворительном состоянии, так же 


\section{Налоги и налогообложение 9(147) • 2016}

осуществляется за счет доходов, остающихся после налогообложения. [4]

При всем различии мнений, следует признать, что, в целом, взимание налога с жилой недвижимости является справедливым, так как в фокусе целевого использования средств этого налога находится непрерывное поддержание и развитие общественной инфраструктуры и инженерных коммуникаций общего пользования, неразрывно связанных с жильем и оказывающих значимое воздействие на его рыночную стоимость.

Рассуждения, связывающие рост расходов на жилье с введением налога на недвижимость, необходимо расширить, так как в идеале следует сравнивать маржинальные расходы и маржинальные выгоды, которые приносит налог. В этом случае справедливость проявляется в различиях различий между маржинальными выгодами и расходами нажилье, отличающееся друг от друга ценообразующими факторами. [5]

Что касается приобретения жилья и налога на жилье, то здесь следует отделять текущие расходы от капитальных. Приобретение жилья и его ремонт - это капитальные расходы, в то время, как поддержание инфраструктуры, обеспечиваемое налогом на жилье - это текущие расходы, которые несет владелец жилья.

Итак, если считать, что вопрос о справедливости решен в пользу налогообложения жилья, то следует дать ответ на следующий вопрос, а именно: какой метод налогообложения будет укладываться в рамки справедливости.

Вопрос о методе налогообложения на доходы физических лиц в начале двадцатого века был решен в пользу прогрессивного налогообложения. Вагнер А., Исаев А., Озеров И., Селигмен Э., Соболев М. и др. были весьма убедительны в том, что подоходный налог, использующий механизм прогрессивного налогообложения, и необлагаемый налогом минимум доходов, является инструментом справедливого распределения налогового бремени, и, как следствие, справедливой реализации распределительной функции налога.

Нет никаких ограничений, чтобы эту концепцию перенести в поле налога на жилое недвижимое имущество. Тогда справедливым будет:

- Использование прогрессивного метода налогообложения жилья.
- $\quad$ Определение необлагаемого налогом минимума общей площади жилья, принадлежащего одному собственнику.

Таким образом, налогоплательщики, владеющие одинаковым жильем, должны нести одинаковое налоговое бремя или, перефразируя, налогоплательщики, владеющие разным жильем, должны нести разное налоговое бремя. T.e. налогообложение должно укладываться в рамки как вертикальной, так и горизонтальной равномерности.

Попытки многочисленных авторов (К. Менгер, А. Исаев, Н. Тургенев, К. Викселль, Э. Линдаль, А. Пигу, Дж. Кейнс, П. Кругман, Ю. Шмелев и др.) на протяжении длительного периода времени формализовать понятие справедливости налогообложения, говоря математическим языком, напоминают асимптотическую сходимость к горизонтальной и вертикальной равномерности, на которые накладывается проблема общественной эффективности налогов. [6]. Общественная эффективность выступает, как целевая функция, максимум которой следует найти при выполнении малоформализуемых условий справедливости налогообложения.

Конструкции вертикальной и горизонтальной равномерности просты и очевидны только в теории. Горизонтальная равномерность требует взимания налога одной величины с плательщиков, находящихся в равном экономическом положении, а равномерность по вертикали, требует взимания налога разной величины с плательщиков, находящихся в разном экономическом положении. В изменяющихся экономических и политических условиях, понятие справедливости меняется, а горизонтальная и вертикальная равномерность становятся общим местом, так как в идеале следует учитывать массу социально-экономических условий и обстоятельств, задача обоснованного выделения которых, при дифференциации налогообложения, не находит выхода из теоретического поля. [7], [8].

Кроме того, не следует забывать об общественной эффективности налога и стоимости администрирования, которые находятся в противофазе к справедливости, так как в идеале справедливость требует тонкого учета многих факторов, определяющих экономическое состояние собственников жилья, что объективно 


\section{Налогообложение физических лиц}

увеличивает стоимость администрирования и снижает общественную эффективность налога.

Если перейти в область оценки справедливости размера налога, то рыночная стоимость жилья может служить некоторым формальным ориентиром справедливости используемых моделей налогообложения жилой недвижимости.

В теории и практике массовой оценки стоимости недвижимости для целей налогообложения применяется инструмент, называемый ценовым дифференциалом, который базируется на средних и средневзвешенных значениях относительной стоимости (отношение оценки к цене) и позволяет диагностировать вертикальную равномерность, порождаемую используемой моделью массовой оценки [9, с. 362].

Значение ценового дифференциала позволяет сделать вывод о прогрессивности, регрессивности и равномерности оценки относительно критерия рыночной стоимости.

Применим этот инструмент для оценки вертикальной равномерности налога, генерируемого действующей моделью налогообложения.

$$
V T D=\frac{\frac{1}{N} \sum_{1}^{N} \frac{T_{i}}{P_{i}}}{\sum_{1}^{N} T_{i}},
$$

где

- VTD - дифференциал вертикальной равномерности налогообложения;

- $T_{i}$ - размер налога на і-тый объект жилой недвижимости;

- $P_{i}$ - рыночная стоимость і-того объекта жилой недвижимости;

- $\quad N$ - количество объектов в выборке;

- $\frac{T_{i}}{P_{i}}-$ относительный показатель доли налога

- $\frac{1}{N} \sum_{1}^{N} \frac{T_{i}}{P_{i}}$ - среднее значение относительного показателя доли налога в рыночной стоимости жилья по выборке;
- $\frac{\sum_{1}^{N} T_{i}}{\sum_{1}^{N} P_{i}} \begin{gathered}\text { средневзвешенное значение относи- } \\ \text { рыного показателя доли налога в }\end{gathered}$ выборке.

С помощью дифференциала вертикальной равномерности налогообложения будем делать вывод о:

1. регрессивности модели налогообложения жилья - снижении доли налога в рыночной стоимости у относительно дорогих объектов жилой недвижимости;

2. прогрессивности модели налогообложения жилья - повышении доли налога в рыночной стоимости у относительно дорогих объектов жилой недвижимости;

3. пропорциональности модели налогообложения жилья - равенстве доли налога в рыночной стоимости у объектов жилой недвижимости разных по стоимости.

Для оценки вертикальной равномерности налога воспользуемся значениями, ценового дифференциала, применяемыми в практике массовой оценки недвижимости для целей налогообложения [10] и принципами налогообложения жилой недвижимости. [11]

Для проведения оценки справедливости, рассмотрим модель налогообложения жилья (2), действующую в Кыргызской Республике.

$$
\mathrm{HC}=\mathrm{C} \times \Pi \times \mathrm{Kp} \times \mathrm{K} 3
$$

где:

- НС - налогооблагаемая стоимость жилья, сом;

- $\quad$ C - налогооблагаемая стоимость одного квадратного метра площади жилья, зависящая от материала стен и возраста жилья, сом/м2;

- $\quad$ П - общая площадь жилья, уменьшенная на площадь, не подлежащую налогообложению, м2;

- Кр - региональный коэффициент, учитывающий изменение налогооблагаемой стоимости жилья в зависимости от его местонахождения на территории Кыргызской Республики; 


\section{Значения дифференциала вертикальной равномерности налогообложения и их интерпретация}

\begin{tabular}{|c|l|c|c|}
\hline \multicolumn{1}{|c|}{ VTD } & \multicolumn{1}{|c|}{ Интерпретация } & Справедливость & Тип налогообложения \\
\hline $0,98-1,03$ & $\begin{array}{l}\text { Равная доля налога в рыночной стоимости } \\
\text { объектов жилой недвижимости }\end{array}$ & Не соблюдается & Пропорциональный \\
\hline$<0,98$ & $\begin{array}{l}\text { Повышение доли налога в рыночной } \\
\text { стоимости у дорогих объектов жилой } \\
\text { недвижимости относительно дешевых }\end{array}$ & Соблюдается & Прогрессивный \\
\hline$>1,03$ & $\begin{array}{l}\text { Снижение доли налога в рыночной } \\
\text { стоимости дорогих объектов жилой } \\
\text { недвижимости относительно дешевых }\end{array}$ & Не соблюдается & Регрессивный \\
\hline
\end{tabular}

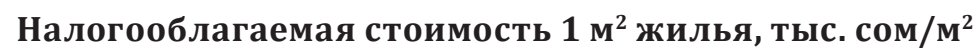

\begin{tabular}{|c|c|c|c|c|c|c|}
\hline \multirow{2}{*}{$\begin{array}{c}\text { Возраст } \\
\text { строения, } \\
\text { лет }\end{array}$} & \multicolumn{7}{|c|}{ Материал стен } \\
\cline { 2 - 7 } & Кирпич & Дерево & Бетон & Сырцовая глина & Шлакоблок & Металл \\
\hline до 5 & 15 & 13 & 14 & 10 & 9 & 7 \\
\hline $5-15$ & 14 & 12 & 13 & 9 & 6 \\
\hline $15-30$ & 13 & 11 & 12 & 6 & 6 & 5 \\
\hline $30-45$ & 12 & 10 & 11 & 5 & 8 \\
\hline
\end{tabular}

Площадь жилья, не подлежащая налогообложению в зависимости от размера населенного пункта

\begin{tabular}{|c|c|c|c|c|c|c|c|c|}
\hline Население, тыс. чел. & $<=5$ & $5-10$ & $10-20$ & $20-50$ & $50-100$ & $100-200$ & $200-500$ & $>=500$ \\
\hline Жилой/дачный дом, м² & 360 & 330 & 300 & 270 & 240 & 210 & 180 & 150 \\
\hline Квартира, м & 290 & 260 & 230 & 200 & 170 & 140 & 110 & 80 \\
\hline
\end{tabular}

- Кз-зональный коэффициент, учитывающий изменение налогооблагаемой стоимости объекта в зависимости от его местоположения в населенном пункте.

В таблице 2 и таблице 3 представлены значения налогообразующих факторов, закрепленные в Налоговом Кодексе Кыргызской Республики.
Для расчета значения VTD - вертикальной равномерности налогообложения, рассмотрим случайную бесповторную выборку из 68 объектов жилой недвижимости, продававшихся на открытом рынке г. Бишкек (столица Кыргызской Республики, население около 1 млн. человек) летом 2015 г. 


\section{Налогообложение физических лиц}

Площадь объектов варьирует от 18 до 360 м². Распределение жилья по территории города не представляет интереса, так как абсолютное большинство объектов - 88\%, попало в зоны с зональным коэффициентом равным 1,2 (особенности действующего зонирования г. Бишкек). Стоимость предложения $1 \mathrm{~m}^{2}$ жилья в выборке варьирует от 375 до 2026 долларов США (в Кыргызской Республике рынок недвижимости оперирует долларами США), со средним значением равным 936 долларов США, при этом 44\% объектов имеют удельную стоимость выше 1 тыс. долларов США.

В качестве рыночной стоимости возьмем стоимость предложения, при допущении, что процентная скидка при продаже будет одинаковой у всех продавцов.

Расчет дифференциала вертикальной равномерности налогообложения, проведенного на выборке, до вычета необлагаемой налогом площади жилья, дал значение VTD = 0,99, что, в соответствии с таблицей 1 , позволяет отнести используемую модель налогообложения жилой недвижимости к несправедливой, так как не реализуется принцип прогрессивности. Однако, после применения вычета, имеющего отношение к площади жилья, VTD принимает значение равное 0,41 , что искусственным образом делает модель налогообложения прогрессивной.

Такой подход к налогообложению жилья говорит о маскировке изъянов модели.

Рассмотрим более подробно, где и каким образом происходит нарушение принципа справедливости. Из рисунка 1 видно, что эффективная ставка налога, до применения вычета необлагаемой налогом площади, для каждого жилого объекта различна и варьирует в диапазоне от $0,04 \%$ до $0,23 \%$ рыночной стоимости жилья. В целом эта величина меньше, чем озвученная в действующем Налоговом Кодексе в размере $0,35 \%$. Однако, из рисунка 1 также видно, что эффективная ставка падает с ростом рыночной

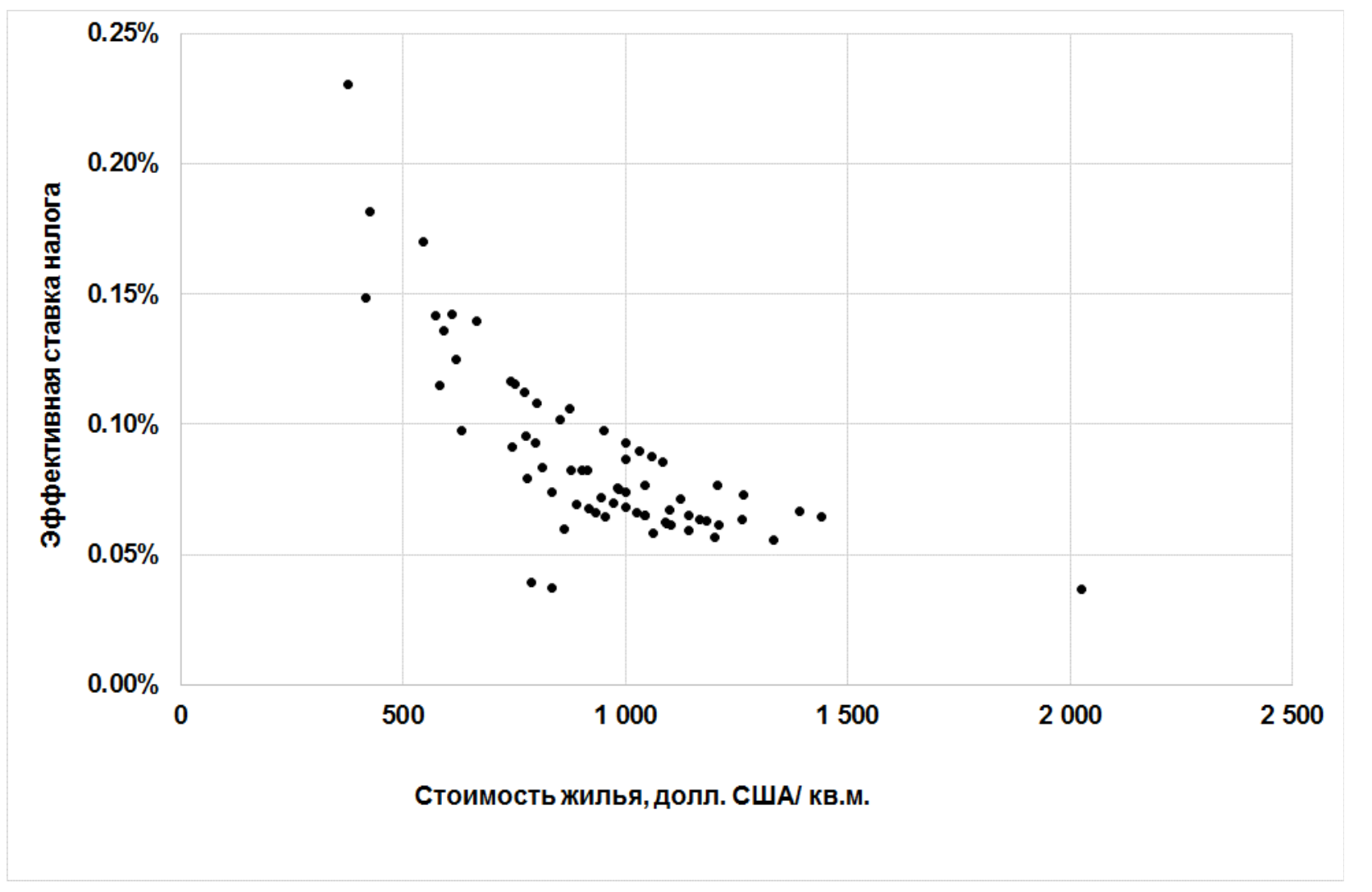

Рис. 1. Зависимость эффективной ставки налога от рыночной стоимости жилья, до вычета необлагаемой налогом площади 


\section{Налоги и налогообложение 9(147) • 2016}

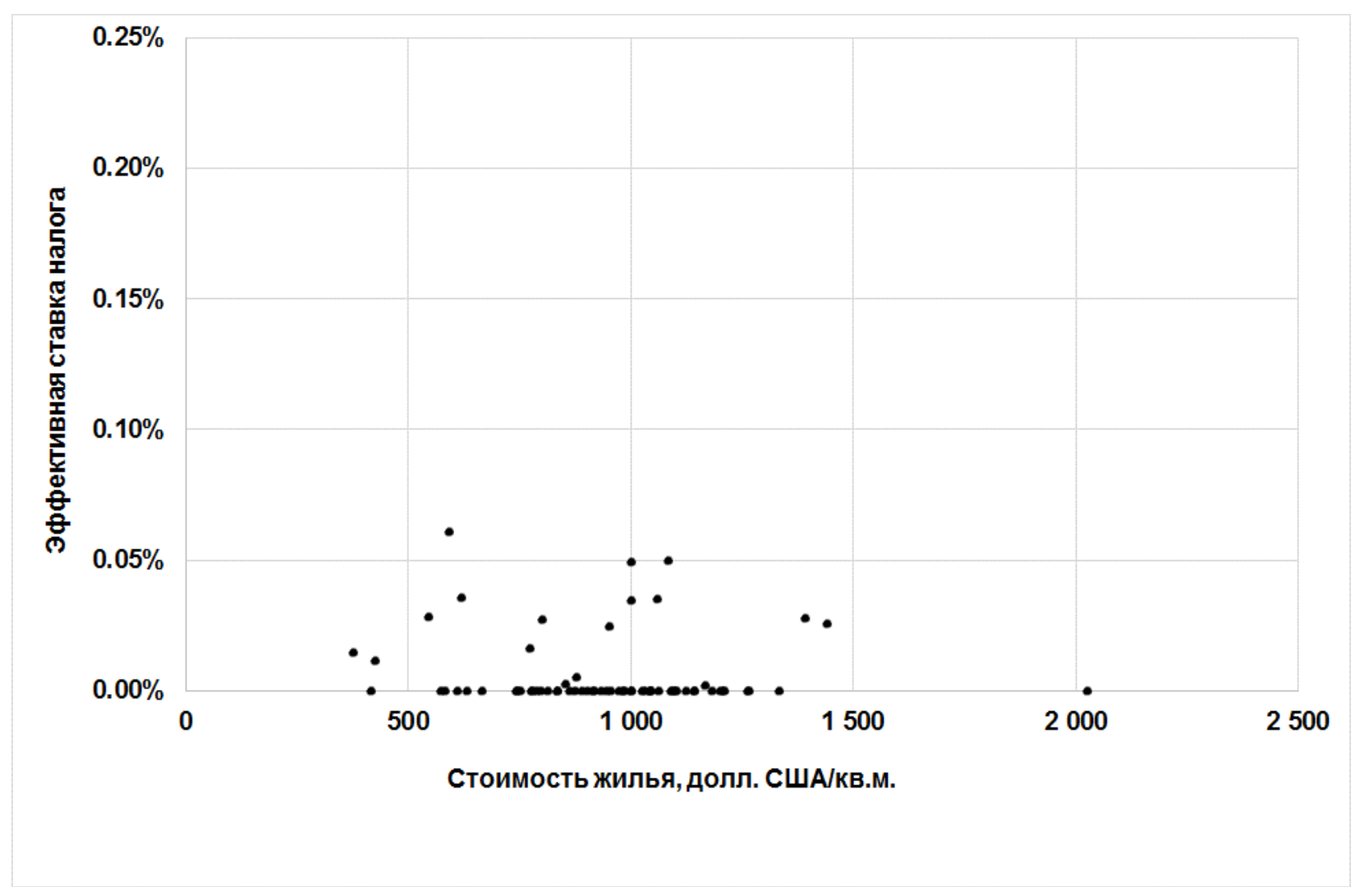

Рис. 2. Зависимость эффективной ставки налога от рыночной стоимости жилья, после вычета необлагаемой налогом площади

стоимости 1 м² жилья. Следует отметить, что именно удельная стоимость жилья является кумулятивным показателем, одновременно учитывающим все факторы, за которые покупатели готовы платить. Разброс точек на рисунке 1 хорошо описывается логарифмическим трендом, коэффициент детерминации, при параметризации которого, составил 70\%. На используемой выборке разница в эффективной ставке налога достигает пятикратного размера.

После применения вычета необлагаемой площади жилья из общей площади жилья, большая часть жилых объектов - 75\% выборки, выпадает из-под налогообложения, а в оставшейся части эффективная ставка налога варьирует от 0,01\% до $0,06 \%$.

Проведенный анализ справедливости налогообложения на выборке показал, что в действующей в Кыргызской Республике модели налогообложения основным фактором, влияющим на сам факт налогообложения является размер общей площади (модель налогообложения является прогрессивной по отношению к общей площади жилья, но это имеет лишь косвенное отношение к экономическому положению субъекта налогообложения), а все остальные факторы, учитываемые в модели имеют незначительный разброс, что делает модель налогообложения, до вычета необлагаемой налогом общей площади, несправедливой, а реализуемый метод налогообложения - приближенным к регрессивному. Недостаток модели маскируется значительной по величине площадью, не облагаемой налогом.

Ихотя на практике принцип прогрессивности налогообложения жилья соблюдается, методологическая основа модели налогообложения не может быть признана справедливой.

Таким образом, приведенные в статье рассуждения позволяют сделать выводы:

- $\quad$ налогообложение жилья, в целом, и прогрессивность метода налогообложения, в частности, имеют справедливый характер; 


\section{Налогообложение физических лиц}

- основные проблемы справедливого налогообложения жилья связаны с выработкой методологии и практикой ее реализации в виде модели налогообложения;
- дифференциал вертикальной равномерности - VTD, может служить формальным инструментом для оценки справедливости налогообложения.

\section{Библиография}

1. Глуховский Я.Ю. Принцип справедливости в налогообложении: прошлое или настоящее// Современные проблемы теории налогового права (The Modern Problems of Tax Law Theory). Материалы международной научной конференции. Воронеж, 4-6 сентября. Воронеж: Воронеж. ун-т, 2007. 40-46 с.

2. Однокоз В.Г. Зарубежный опыт налогообложения имущества // Гуманитарные научные исследования. 2015. №3. 2015. URL: http://human.snauka.ru/2015/03/8587.

3. Белова Г.Ю. Проблемы и перспективы реформирования налогообложения жилой недвижимости // Научные труды: Институт народнохозяйственного прогнозирования РАН, №8, 2010. с. 213-238.

4. Шмелев Ю.Д.. Концепция реформирования налоговой системы Российской Федерации, основанная на реализации принципа справедливости и социальной функции налогов: автореф. дис... д-р. экон. наук: 08.00.10. М., 2008. 57 с.

5. Мокроусов Н.В. Чувствительность стоимости жилой недвижимости к влиянию факторов различной природы // Вестник Кыргызско-Российского Славянского Университета; КРСУ, №6, 2012. c. $164-167$.

6. Гульбина Н.И. Экономисты ХХ в. О влиянии налогов на экономическую активность // Вестн. Том. гос. ун-та. Экономика. 2014. №1 (25). URL: http://cyberleninka. ru/article/n/ekonomisty-hh-v-o-vliyanii-nalogov-na-ekonomicheskuyu-aktivnost.

7. Майбуров И.А., Соколовская А.М. Теория налогообложения. Продвинутый курс// М., 2011.

8. Юрьев В.М., Филатова И.И. Налог на доходы физических лиц как инструмент реализации принципа справедливости в гражданском обществе // Вестник ТГУ. 2012. №3. URL: http://cyberleninka. ru/article/n/nalog-na-dohody-fizicheskih-lits-k.

9. Эккерт Дж.К. Организация оценки и налогообложения недвижимости // Т. 1. М: СТАР-ИНТЕР, 1997. 382 c.

10. Международные стандарты оценки //2007.

11. Лукашова И.В. Принципы налогообложения жилой недвижимости // Налоги и налогообложение. - 2016. - №4. - С. 359-363. DOI: 10.7256/1812-8688.2016.4.18623.

12. Шмелев Ю.Д. Актуальные проблемы управления - 2003: Материалы международной научнопрактической конференции: Вып.4. // Налог на доходы физических лиц в РФ и принцип справедливости. М.:ГУУ. 2003.

13. Фокина М.М. Купля-продажа жилой недвижимости: современные правовые проблемы // Урбанистика и рынок недвижимости. - 2014. - 2. - C. 92 - 97. DOI: 10.7256/2313-0539.2014.2.11706.

\section{References (transliterated)}

1. Glukhovskii Ya.Yu. Printsip spravedlivosti v nalogooblozhenii: proshloe ili nastoyashchee// Sovremennye problemy teorii nalogovogo prava (The Modern Problems of Tax Law Theory). Materialy mezhdunarodnoi nauchnoi konferentsii. Voronezh, 4-6 sentyabrya. Voronezh: Voronezh. un-t, 2007. 40-46 s.

2. Odnokoz V.G. Zarubezhnyi opyt nalogooblozheniya imushchestva // Gumanitarnye nauchnye issledovaniya. 2015. №3. 2015. URL: http://human.snauka.ru/2015/03/8587.

3. Belova G.Yu. Problemy i perspektivy reformirovaniya nalogooblozheniya zhiloi nedvizhimosti // Nauchnye trudy: Institut narodnokhozyaistvennogo prognozirovaniya RAN, №8, 2010. c. 213-238. 


\section{Налоги и налогообложение 9(147) • 2016}

4. Shmelev Yu.D.. Kontseptsiya reformirovaniya nalogovoi sistemy Rossiiskoi Federatsii, osnovannaya na realizatsii printsipa spravedlivosti i sotsial'noi funktsii nalogov: avtoref. dis... d-r. ekon. nauk: 08.00.10. M. 2008. 57 s.

5. Mokrousov N.V. Chuvstvitel'nost' stoimosti zhiloi nedvizhimosti k vliyaniyu faktorov razlichnoi prirody // Vestnik Kyrgyzsko-Rossiiskogo Slavyanskogo Universiteta; KRSU, №6, 2012. c. 164-167.

6. Gul'bina N.I. Ekonomisty khkh v. O vliyanii nalogov na ekonomicheskuyu aktivnost' // Vestn. Tom. gos. un-ta. Ekonomika. 2014. №1 (25). URL: http://cyberleninka. $\mathrm{ru} / \mathrm{article/n/ekonomisty-hh-v-o-vliyanii-nalogov-na-ekonomicheskuyu-aktivnost.}$

7. Maiburov I.A., Sokolovskaya A.M. Teoriya nalogooblozheniya. Prodvinutyi kurs// M., 2011.

8. Yur'ev V.M., Filatova I.I. Nalog na dokhody fizicheskikh lits kak instrument realizatsii printsipa spravedlivosti v grazhdanskom obshchestve // Vestnik TGU. 2012. №3. URL: http://cyberleninka. ru/article/n/nalog-na-dohody-fizicheskih-lits-k.

9. Ekkert Dzh.K. Organizatsiya otsenki i nalogooblozheniya nedvizhimosti // T. 1. M: STAR-INTER, 1997. $382 \mathrm{~s}$.

10. Mezhdunarodnye standarty otsenki //2007.

11. Lukashova I.V. Printsipy nalogooblozheniya zhiloi nedvizhimosti // Nalogi i nalogooblozhenie. - 2016. - №4. - S. 359-363. DOI: 10.7256/1812-8688.2016.4.18623.

12. Shmelev Yu.D. Aktual'nye problemy upravleniya - 2003: Materialy mezhdunarodnoi nauchno-prakticheskoi konferentsii: Vyp.4. // Nalog na dokhody fizicheskikh lits v RF i printsip spravedlivosti. M.:GUU. 2003.

13. Fokina M.M. Kuplya-prodazha zhiloi nedvizhimosti: sovremennye pravovye problemy // Urbanistika i rynok nedvizhimosti. - 2014. - 2. - C. 92 - 97. DOI: 10.7256/2313-0539.2014.2.11706. 